ФИННО-АМЕРИКАНСКАЯ ИДЕНТИЧНОСТЬ

И СТРАТЕГИИ ЕЕ ОПРЕДЕЛЕНИЯ

В СОВРЕМЕННОЙ ФИННО-АМЕРИКАНСКОЙ

ЛИТЕРАТУРЕ

Статья посвящена одной из актуальных проблем современного гуманитарного знания - проблеме самоидентификации гибридных культур, в частности, финно-американской. Этническое многообразие США ведет к постоянному пересечению различных культур, порождающему своеобразие современной литературной жизни Америки. Национальная, культурная, личностная идентичность, связанная с пересмотром усвоенных в своей диаспоре традиций, выступает в качестве главной проблемы мультикультурализма - идеологии множественности и многообразия. Самоидентификация осуществляется, как правило, через определение своей религиозной, этнической, гендерной детерминации. Очень часто стратегиями самоидентификации становятся переживаемая сообществом коллективная травма и коллективная память об историческом прошлом. В качестве основных стратегий самоидентификации финно-американской литературы - этнической и культурной - выступают коллективная память, коллективная травма, «финскость» и национальный карело-финский эпос «Калевала», используемый как источник архетипических образов и поэтического воображения.

На материале ряда произведений разных жанров (фантастика, исторический роман, рассказы) финноамериканских писателей второй половины XX - начала XXI в. в статье рассматривается творческое использование карело-финского эпоса «Калевала», встроенного в опыт американского существования в качестве одной из основных стратегий самоидентификации собственной культуры, сформированной в диалогическом взаимодействии двух культур - англо-саксонской и финской. В статье актуализируются проблемы диалогического взаимодействия культур, трансформации архетипических образов, отражения коллективной памяти в художественном творчестве современных финно-американских писателей.

Ключевые слова: финно-американская литература, гибридная идентичность, диалог культур, мультикультурализм, коллективная память, «финскость», «Калевала», Эмиль Петайя, Лори Андерсон, Карл Марлантес.

DOI: $10.35634 / 2224-9443-2021-15-4-642-653$

Особый колорит американской культуре обеспечило постоянное соприкосновение многочисленных этносов и различных рас, разных по своему характеру регионов, различных религий. Динамика и изменчивость американской нации, находящейся в состоянии постоянного вторжения разнообразных культур, в сущности, показывает пример настоящего диалога культур, сферу перманентного взаимопересечения и взаимоналожения различных семиосфер и трансформаций культурно-семиотических систем.

При этом, как утверждал М. М. Бахтин, диалог культур должен пониматься не как простое общение, речевая деятельность, а как взаимное самопознание и самоутверждение, как существование «Своего» в «Другом», и самосознание культуры есть форма её бытия на грани 
с иной культурой [Бахтин 1979]. Кроме того, современные исследователи американской мультикультурности справедливо отмечают, что этот диалог связан не только с утверждением собственной этнической идентичности, но и с ее выживаемостью. [Тлостанова 2000; Кушнарева 2011]. Добавим, что в условиях постколониального мышления второй половины XX в. проблема определения своего «Я» стала центральной в литературной жизни, где границы собственной идентичности устанавливаются посредством разработки таких тем, как история, творчество, коллективная память, оппозиция дом/изгнанничество, о чем достаточно подробно говорят не только американские, но и отечественные литературоведы [Американцы в поисках идентичности 2013; Коллективная память: власть прошлого в социокультурной жизни Америки 2021]. В современной американской литературе дуализм авторского сознания, его объективная принадлежность двум культурам становится ведущим творческим импульсом.

Эти положения специфики современного американского мультикультурализма, диалога двух культур как нельзя лучше демонстрирует финно-американская культура и литература. Современная финская диаспора в США невелика: по последним статистическим данным там проживает около 650000 человек, так или иначе (полностью, наполовину или на четверть) причисляющих себя к финнам. Тем не менее они являются неотъемлемой частью американской этнической мозаики. Без их участия, как и без участия других иммигрантов, немыслима история и культура Америки. Как справедливо отметил американский историк О. Хендлин: «Однажды я решил написать историю иммигрантов в Америке и обнаружил, что иммигранты и есть американская история» [Handlin 1952, 3].

Первые финские поселенцы появились на территории Северной Америки еще в XVII в., когда финские земли находились в составе Швеции. Установлено, что на двух кораблях, прибывших в 1638 г. к берегам Америки, были финны, участвовавшие в формировании первого скандинавского поселения Новая Швеция, основанного на берегах реки Делавэр на территории современных североамериканских штатов Делавэр, Нью-Джерси и Пенсильвания. Память о первых финских поселениях сохранилась на берегах Дэлавера по сей день в названиях населенных пунктов, таких как Финляндия, Лапландия и др. Впоследствии на карте Америки вдоль реки Дэлавер, по мере компактного заселения этих земель финскими переселенцами, на Северо-Западе США, в штатах Мичиган, Миннесота, Висконсин, Огайо появилось достаточно большое количество населенных пунктов с финскими названиями - Лиминга, Улу, Паавола и др.

В XVIII в. первое «финское» описание Нового Света создал финн Пер Калм, профессор Королевской Академии Або (Турку) в Шведской Финляндии. В пространном описании совершенного им путешествия в новые земли с октября 1747 по май 1751 г. (опубликовано в трех томах в 1753-1761 гг. под названием «Путешествие в Северную Америку») он, в сущности, фиксирует восприятие Америки первыми поселенцами, имеющими общий с ним опыт жизни. П. Калм был натуралистом, учеником Карла Линнея, и его взгляд, безусловно, отражает стремление к научной систематизации невиданного доселе мира природы. Вместе с тем, его описания включают в себя впечатления первопроходца, восхищающегося новым миром, отчасти напоминающим тот, откуда он прибыл. Его оптика - это оптика человека, выросшего на фоне лесов и рек Финляндии, поэтому так любовно он описывает открывающиеся ему просторы: «Берега залива Дэлавер песчаные, глубина реки от четырех до одиннадцати морских саженей. По обе стороны залива виднеются великолепные дубовые и ореховые рощи, еловые леса, и эти деревья используются для кораблестроения» [Kalm 1772].

Таким образом, Америка становилась объектом одновременно и новым, и своим, близким. Подобная репрезентация рождала ощущение новых перспектив в прекрасном мире, напоминающем собственный, и служила основанием великого американского социального мифа - американской мечты, манящей европейцев к новым берегам. Такое восприятие Америки отразилось в финском фольклоре, как, например, в финской иммигрантской балладе «Я еду в Америку»: 
I'm going to America

Everyone is on his way.

The American shores are sanded

With gold they say.

I'll embark from Hankoniemi

On a small boat and go.

'Cause Finland can't support

The children of her poor.

[Leonard 2003, 3]
Я еду в Америку,

Свой путь выбирает каждый.

Говорят, американские берега

Сплошь из золотого песка.

Отплыл я от берега Ханко,

На маленькой лодке плыву,

Не может Финляндия больше

Нас прокормить, бедняков.

(перевод мой - И. М.)

Особенно массово финские иммигранты прибывали в США на протяжении XIX в., компактно заселяя районы Северо-Запада. Они становились фермерами, лесорубами, работали на рудниках по добыче меди. Именно тогда появились первые попытки определения собственной идентичности. Так, первая финно-американская газета Amerikan Suomalainen Lehti (Американская Финская Газета) вышла в Мичигане в 1876 г., где первое поколение иммигрантов пыталось передать свой опыт следующим поколениям. Не случайно там публиковались материалы для детей, служащие целям сохранения финского культурного наследия. При этом, как отмечают исследователи, у финнов было настолько сильно развито чувство собственного этнического сообщества, что в течение длительного времени многие из них не говорили по-английски, практически все время общаясь только внутри своей диаспоры и стремясь не американизироваться, а преобразовать новую страну в землю их мечты [Leonard 2003].

Самым активным периодом финской миграции в США были годы с 1870 по 1920: в это время иммигрировало приблизительно 340000 финнов. Эта мощная миграция была вызвана острыми политическими и экономическими проблемами, связанными с процессом обретения Финляндией независимости в 1917 г. Именно эти мигранты стали главными рабочими на медных рудниках Мичигана и Миннесоты и главными распространителями идей социализма не только на территории штатов Северо-Запада США, но и по всей стране [Hoglund 1960]1

Им же в известной мере принадлежит первенство в процессе формирования представления финской диаспоры о себе не просто как о финнах в Америке, но как о финно-американцах, осознающих свою гибридную идентичность. Этот процесс самоидентификации подтверждает известную мысль М. Бахтина о том, что «чужая культура только в глазах другой культуры раскрывает себя полнее и глубже. <..> Мы ставим чужой культуре новые вопросы, каких она сама себе не ставила, мы ищем в ней ответа на эти самые вопросы, и чужая культура отвечает нам, открывая перед нами свои новые стороны, новые смысловые глубины» [Бахтин 1986, 507-508]. Этот постулат М. М. Бахтина объясняет известный казус взаимодействия финской и американской культурной истории, явивший себя в рецепции карело-финского эпоса «Калевала» в Америке.

Традиционно важной ступенью пробуждения идентичности народа является стремление узнать о своих корнях, что влечет за собой обращение к народному эпосу как хранилищу коллективной памяти. Публикация «Калевалы» в 1835 г. стала важным событием для финской культуры, для формирования особой национальной гордости, связанной с декларированием собственной уникальной идентичности. Так, например, один из восторженных отзывов гласил, что «с некоторым преувеличением можно сказать, что только сейчас Финляндия обрела свои истоки. Проникая в этот эпос, она может теперь изучать свою древность и предвидеть курс своего будущего духовного развития. Она может сказать самой себе: и у меня тоже есть история!» [Wargelin-Brown 1994, 184].

По мнению исследователей, «впечатляющее количество рун «Калевалы», воспринятое сквозь призму романтической идеологии и зарождающегося финского национализма, позво-

\footnotetext{
${ }^{1}$ Следует отметить, что многие из них в начале 1930 -х гг. вернулись в Советскую Карелию, послужив своеобразными медиаторами между американской и советской культурой, о чем подробно рассказывает книга А. Голубева и И. Такалы «В поисках социалистического Эльдорадо: североамериканские финны в Советской Карелии 1930-х гг.» СПб., 2019. 
лило сформировать финскую культурную идентичность, находившуюся тогда под контролем Швеции и России» [Leonard 2003, 18]. Таким образом, «в Финляндии “Калевала” очень скоро превратилась в катализатор возникновения финского национализма и финской идентичности, усиления влияния финского языка» [Viihiimiiki 2009, 2].

Действительно, не вызывает сомнения факт, что именно «Калевала» стала стимулом для формирования понимания своего «Я» в финском национальном сознании. Она находится в центре непрекращающихся научных дискуссий: «история формирования финской национальной идентичности посредством «Калевалы» многократно рассказана с разными вариациями и в многочисленных дискуссиях» [Tarkka 2009].

Эпос «Калевала» довольно быстро после первой публикации был переведен на европейские языки. И хотя английский перевод, сделанный Джоном Портером с перевода на немецкий Франца Шифнера 1852 г., появился только в 1868 г., тем не менее мотивы, архетипические образы, архитектоника, метрика этого произведения уже были известны американской читающей публике. Во многом эти знания распространялись благодаря увлечённости мифами и эпосами других стран и народов американских романтиков, которые стремились создать свою национальную литературу. Так, например, Н. Готорн в «Книге чудес» адаптировал античные мифы; В. Ирвинг в «Альгамбре» обращался к трансформированным в Испании арабским сказаниям; Г. Лонгфелло в «Песне о Гайавате» предпринял попытку создания искусственного американского эпоса, основываясь на индейских фольклорных сказаниях и опираясь на архитектонику «Калевалы» и на ее метрический размер - хореальный тетраметр.

Споры вокруг степени влияния и путей знакомства Г. Лонгфелло с «Калевалой» составляют немалую часть американских и финских исследований «Песни о Гайавате». Хотя сам Г. Лонгфелло отрицал прямое влияние «Калевалы», соглашаясь только с тем, что метрическая схема «Калевалы» удачно совпала с такой же в индейских сказаниях, однако влияние, без сомнения, было. Можно предположить, что американский романтик познакомился с первым изданием «Калевалы» еще летом 1835 г., когда во время путешествия в Швецию изучал там финский язык. Так что знакомство Г. Лонгфелло с финским эпосом могло состояться задолго до появления дискуссий о нем в романтическом американском сообществе и напрямую повлиять на создание «Песни о Гайавате».

При этом сами финские иммигранты, по наблюдению исследователей, не разделяли интерес американских романтиков к своему эпосу, поскольку большинство из них было не настолько образованно, чтобы даже слышать о «Калевале». Подобное положение дел сохранялось в XIX в. и вплоть до второй половины ХХ в. [Wargelin-Brown 1994, 190].

Следует упомянуть любопытное свидетельство того, что именно «Калевала» становится фактором, цементирующим новую гибридную идентичность финнов в США в XX в. М. Уоргелин-Браун в исследовании о судьбах «Калевалы» в Америке описывает фотографию, сделанную в штате Огайо 4 июля 1912 г. на празднике в честь 100-летия со дня первого парада Дня Независимости. На фотографии видны две фигуры, стоящие на задрапированном американским флагом пароме - американский индеец напротив вигвама и белобородый древний финн с кантеле в руках. Надпись внизу фотографии гласит: «Гайавата и Вяйнямёйнен». М. Уоргелин-Браун делает справедливый вывод о том, что здесь заметно, как постепенно только в XX в. «Калевала» приобретает определенный статус в американском социокультурном контексте: «Она становится знаком этнической идентичности, используя при этом этнические ярлыки, понимаемые американским окружением. Иными словами, финно-американцы начинают обращать внимание на «Калевалу», потому что Америка сама идентифицирует ее как объект финской культуры» [Wargelin-Brown 1994, 194].

При этом важно отметить, что уже здесь «Калевала» представлена не столько как объект исключительно финской идентичности, но идентичности, осознающей свое пограничное состояние и определяющей себя через эпос, отразившийся в культурном сознании двух народов. Такое сближение весьма символично. Точно так же, как коренное население Америки, индей- 
цы, ощущали себя маргинальной частью США и чувствовали свою неразрывную связь с таинственным миром природы, чуждым цивилизации, точно так же и финская диаспора подчеркивала связь своего духовного мира с миром первозданной природы, о чем еще в 1930-е гг. писали собиратели фольклора. По их мнению, финская диаспора упорно сохраняет мистицизм, древнюю магию, так подходящую северным поселениям, где люди, в отличие от большого города с его высотками, автострадами и автомобилями, все еще передвигаются на лыжах зимой и на каноэ летом. При этом американцы вне этой диаспоры были склонны рассматривать финнов как людей, исповедующих не только христианство, но и язычество, уверяя, что наряду с церквями многие финны посещают шабаши ведьм [Wargelin-Brown 1994].

Во многом такое восприятие базировалось на репрезентации финнов в связи с публикацией в США в 1888 г. первого полного перевода «Калевалы» на английский язык Джона Кроуфорда. В своем предисловии Д. Кроуфорд создает определенную репутацию финнам как людям, склонным к мистицизму и магии, что передается также и посредством языка. Так, Д. Кроуфорд характеризует финский язык как язык людей, живущих на лоне природы, среди зверей, птиц и дикости, среди лесов и рек, обильных снегопадов, суровых скал, - одним словом, финский язык отражает сущность людей, для которых центром вселенной и их главным божеством является суровая природа, а каждое финское слово связано с силами и элементами этой угрюмой природы [Wargelin-Brown 1994].

Однако эти характеристики и мифопоэтическая образность «Калевалы» были по-настоящему оценены самой финской диаспорой США только во второй половине ХХ в. в связи с распространившимися в США постколониальной теорией и идеологией мультикультурализма, ставившими во главу угла определение собственного «Я». «Калевала» стала источником финно-американской идентичности, с одной стороны, а с другой - бесценным ресурсом мотивов, образов и художественного воображения финно-американских писателей, художников и музыкантов.

Опора на «Калевалу» превратилась в главную стратегию определения финно-американской идентичности, прежде всего, в жанре фантастики, который стал очень популярным в «опьяненные» открытием космоса 60-е гг. XX в. Космогонический мотив, мотивы сотворения мироздания, преобразования в «Калевале» как нельзя лучше соответствовали и космической «повестке» дня, и постколониальной. Это позволило финно-американским писателям использовать «Калевалу» как с точки зрения общей тенденции развития фантастической литературы XX в., так и с позиций этнической и культурной самоидентификации.

Как справедливо отмечают исследователи, используя английский язык как средство выражения, вместе с тем финно-американские авторы вновь открывают финские культурные архетипы как средство самоидентификации, используя мифологию «Калевалы» для пробуждения или активизации скрытой финской идентичности в своей аудитории [Virtanen 2009].

Самым значительным вкладом в обозначение «Калевалы» как главной стратегии определения собственной этнической и культурной идентичности стало творчество американского писателя финского происхождения Эмиля Петайи [Emil Petaja 1915-2000], обладателя престижных премий по литературе в области фантастики. Его перу принадлежит достаточно большое количество произведений, которые являют собой интересное сочетание элементов научной фантастики (путешествия в космосе, противостояние различных миров и измерений, инопланетяне) и фэнтези (мифологические мотивы и герои «Калевалы»). Наличие нарратива фэнтези, безусловно, было спровоцировано грандиозной популярностью «Властелина колец» Дж. Толкина, вышедшего в 1955-1956 гг. Однако важным является то, что Э. Петайя, создавая свою Вселенную, в отличие от последователей Дж. Толкина, опирается исключительно на финский эпос.

Наибольший интерес с точки зрения использования «Калевалы» представляет, прежде всего, его трилогия «Космическая Калевала» (The Cosmic Kalevala): «Книга 1: Сага о потерянных Землях» [Book One: The Saga of Lost Earths 1966], «Книга 2: Звездная мельница» [Book Two: The Star Mill 1966], «Книга 3: Украденное солнце» [Book Three: The Stolen Sun 1967]. Интерес- 
но, что Э. Петайя подтверждает мысль о том, что «Калевала» до этого времени не была центральным объектом, определяющим финно-американскую идентичность. Так, в предисловии к «Книге 2: Звездная мельница» он поясняет, что эта книга, как и предыдущая, была написана «на основе мало известного (выделено мной - И. М.) финского эпоса "Калевала"» [Реtaja $2005,3]$. Сам же писатель активно использует все основные мотивы и образы этого эпоса. Так, в каждой книге происходит перерождение главных героев Калевалы в далеком будущем, где им предстоит противостоять злым силам - инопланетянам пахалисетам (безусловно, самим названием связанным с Похьелой, вечной соперницей Калевалы), которые единожды в далеком прошлом пытались завоевать Финляндию. В первой книге действуют далекие потомки эпического богатыря Лемминкяйнена, которые стремятся спасти Вселенную.

Книга 2, как следует уже из ее названия, обращается к эпической истории мельницы Сампо, созданной знаменитым кузнецом Илмариненом. Здесь звездная колдунья Лоухи, одна из предводителей пахалисетов, овладевает Сампо и при помощи заклинаний превращает ее из силы созидания в силу разрушения. Вспомним, что в «Калевале» Лоухи, злая и коварная колдунья, а также владычица государства Похьелы, противостоит песнопевцу богатырю Вяйнямёйнену. В третьей книге «Украденное солнце» главный герой Уэйн продолжает сражаться с Лоухи и возглавляемыми ею пахалисетами. На помощь ему приходит сам Вяйнямёйнен, путешествующий в космическом пространстве на каноэ.

Каждую книгу предваряет отрывок из рун, соответствующих ее сюжету, что еще больше связывает повествование с эпосом. Эти отрывки могут рассматриваться как эпиграфы, которые подчеркивают главную тематическую составляющую романов и служат своеобразным кодом чтения, позволяющим понять глубинные связи повествования с «Калевалой». Так, в первой книге Э. Петайя обращается к руне 9 о происхождении железа: изначально предназначенное кузнецом Илмариненом к добру, оно изменило своей клятве и дало рождение злу. Во второй книге эпиграфом становится отрывок из руны 43 о том, как злая колдунья Лоухи послала воинов Похьелы вдогонку за похитителями Сампо, что практически полностью соответствует сюжету книги. Третья книга открывается 47 руной о том, как Лоухи похитила солнце и месяц и холодная ночь опустилась на Калевалу, а Вяйнямёйнену предстоит последний бой со злом, что, в сущности, в общих чертах происходит и в последней книге трилогии. Важной идеей романов Э. Петайи является утверждение генетической связи древних финнов и их потомков в далеком будущем, и соединяющим звеном здесь становится эпос «Калевала», в котором прошлое, настоящее и будущее вовлечены в единый дискурс финской идентичности.

Стратегия обозначения идентичности посредством «Калевалы» успешно формирует и другие стратегии самоидентификации, одной из которых является определение того, каковы сущностные стороны финского характера, что объединяет всех финнов, вне зависимости от места их проживания, иными словами - что такое «финскость».

Как отмечают исследователи, на территории Америки практически до начала XX в., пока финская иммиграция не привела к резкому росту числа финнов, у большинства американцев англо-саксонского происхождения сложилось довольно стереотипное представление о финнах как о людях «неразговорчивых, меланхоличных, рассудительных, приверженных своему клану, терпеливых, угрюмых <...> большинство их склонно к выпивке, дракам и радикализму <..>. В то время как некоторые из этих характеристик верны (клановая приверженность и терпеливость), в целом же финские иммигранты представляли собой вполне жизнерадостную группу. Они любили хорошо посмеяться, и часто их смех был направлен на себя. Остроумие высоко ценилось финнами» [Hoglund 1960, 125]. «Финскость» определяется сущностными культурными кодами, к числу которых относится «маскулинная культура лютеранства, выразившаяся в виде трудолюбивых, эмоционально сдержанных мужчин и их помощниц - трудолюбивых, эмоционально сдержанных женщин» [Dykstra 2008, 46].

Однако, по утверждению ученых, наиболее важным персональным и общим поведенческим индикатором «финскости» является “sisu”, уникальный концепт, определяющий финский 
характер. “Sisu” включает в себя такие характеристики как «усердие, чистоплотность, готовность оказать помощь, честность, сдержанность и алкогольные привычки» [Taramaa 2009, 58]. К числу самых упоминаемых характеристик “sisu” относится своеобразное упрямство: «Что бы ни должно быть сделано, оно будет сделано, несмотря ни на что. Это качество, которое помогает им смеяться над собой перед лицом невзгод <..>. В двух словах, это неукротимая сила воли» [Rajanen 1984, 10]. И, что очень примечательно, именно “sisu” «идет рука об руку со своевольным духом “Калевалы”» [Leonard 2003, 12].

Не случайно финно-американские писатели обращаются к "sisu” как главному духовному наследию «Калевалы», формирующему финскую идентичность. Такая мысль проводится, например, Лори Андерсоном (Lauri Anderson, 1942) в сборнике рассказов «Дети Калевалы: современное возрождение американскими финнами бессмертных сказаний Калевалы» (Children of the Kalevala: Contemporary American Finns Relive the Timeless Tales of Kalevala, 1997). Сам Л. Андерсон всегда подчеркивает свою принадлежность к финно-американской диаспоре. Так, в одном из своих интервью Л. Андерсон отмечает: «Я вырос в маленьком изолированном городке Монсон, штат Мэн, где добывают сланец. Люди Монсона были из рабочего класса, близкие к земле и суровые <...>. Многие говорили по-фински дома и по-английски на публике. Они были практичны и закалены. Они рано старели. Они проводили долгие изнуряющие часы на работе и пили все выходные подряд < ..>. Бедность сделала их доброжелательными в целом, но грубыми к тем, кто им противоречил» [Encyclopedia com...].

В сборнике «Дети Калевалы» Л. Андерсон рисует именно таких персонажей, отличающихся особым финским характером с духом "sisu”. В предисловии к сборнику писатель иронически характеризует специфику финно-американцев, проживающих в районе Верхнего полуострова Мичигана (Upper Peninsula of Michigan), чье прозвище Yooper происходит от аббревиатуры географического названия - UP (Upper Peninsula). Коллективный портрет Yooper выглядит так: «Yooper водит очень старый и ржавый пикап, плотно декорированный наклейками для бампера, призванными для того, чтобы пикап не развалился <...>. Ружье, удочка и собака располагаются в кабине, но иногда там может быть и ребенок, если он болен. Обычно же жена, дети и кот едут в кузове. Самое любимое занятие Yooper - пить пиво "Old Milwaukee" в местном баре. Yooper живет от одной банки пива к другой <...>. Когда он печален, то может не разговаривать днями, но когда выпьет, то очень любит поболтать. Тут он может заговорить всех и каждого, пока те в состоянии слушать. И одна из его любимых тем - это его отношения с другими. Он знает даже тех, кто живет за сотню миль, или, по крайней мере, претендует на то, что знает <..>. И, наконец, Yoоper определяется, хотя бы частично, «Калевалой», национальным эпосом Финляндии. В «Калевале» полно героических фигур из лесной глуши, которые совершают великие дела в языческом мире» [Anderson 1997 III-IV].

Все восемь рассказов этого сборника демонстрируют неразрывную связь «финскости» с «Калевалой», поэтому в каждом из них в качестве подзаголовка указаны номер руны и название одного из ее сюжетов, например: «Ууно Персонен. Руна 46 - Битва с медведем», и иронически обыгрываются деяния мифических героев в контексте обыденной жизни современных финно-американцев. Как Л. Андерсон с юмором отмечал в вышеприведенном интервью, в «Калевале» Вяйнямёйнен перебирал струны своей магической арфы и тем самым загнал врагов в болото, а в северном Мичигане рок-группа может сыграть так громко, что даже бабушку убьет» [Encyclopedia. com.]. Таким образом, ставя перед собой задачу проникновения в сущность финно-американской идентичности, Л. Андерсон избирает стратегию описания «финскости» и использует юмор и иронию как адекватный способ ее репрезентации.

Проблема соотношения американизации и сохранения национальных традиций иммигрантов в творчестве писателей с гибридной этнической идентичностью тесным образом связана с проблемой исторической памяти как важнейшей формой духовной активности. Общая тенденция постколониального мышления с его категориями коллективной памяти и коллективной 
травмы заставляет финно-американских писателей также обращаться к ним как к стратегиям самоидентификации.

Самым ярким примером и, пожалуй, самым значительным произведением последних лет, созданным финно-американским писателем, является роман-эпопея Карла Марлантеса [Karl Marlantes 1944] «Глубокая река» [Deep River 2019]. Эта объемная семейная сага, повествующая об адаптации финнов в течение четырех десятилетий на американской земле, начинается в 1891 г. в Финляндии с события, «о котором впоследствии никогда не говорили, но никогда не забывали» [Marlantes 2019, 4]. Майялиса Коски возвращается после трехдневного отсутствия домой (она помогала в родах живущей неподалеку бедной шведке) и обнаруживает, что трое из ее шестерых детей умерли от холеры.

Эта трагедия предопределяет характер и судьбу оставшихся в живых детей. Трехлетняя Айно «вбирает в себя одиночество», порождающее мужество, которое впоследствии помогает ей выжить в нескончаемых жизненных испытаниях. Двенадцатилетний Илмари увидел в своих мертвых сестрах и брате ангелов, посланных Богом, и это определяет его религиозное чувство. Двухлетний Матти, самый младший, не осознавал ничего, но сама ситуация породила неуверенность и страх перед будущим. Так К. Марлантес актуализирует проблему коллективной травмы, оказавшей самое значительное влияние на жизнь этой семьи, которая в самом общем виде представляет собой собирательный образ всех финских иммигрантов. Вся их дальнейшая жизнь - это попытка преодолеть полученный травмирующий опыт у себя на родине.

Судьба семьи практически сразу переплетается с Америкой: в 1901 г. Илмари, дабы избежать воинской повинности в русской армии, уезжает сюда и удачно перепродает доставшиеся ему по государственной программе 160 акров земли: «В четыре раза больше, чем ферма в Финляндии, которую Тапио и Майялиса (отец и мать - И. М.) обрабатывали в течение многих лет, но принадлежала она богатому аристократу. В Америке нет аристократов, и правительство здесь раздает земли бесплатно. Соединенные Штаты, должно быть, уже социалистическая страна» [Marlantes 2019, 25]. Однако он считает слишком тяжелым труд по корчеванию деревьев и мечтает продать часть земли, дабы заняться кузнечным делом, что, как и его имя, безусловно, связывает этот персонаж с образом искусного кузнеца Илмаринена из «Калевалы».

В то время как Илмари устраивает свою жизнь в Америке, семья претерпевает очередные невзгоды, получает новый травмирующий опыт: в результате драки с русскими офицерами Тапио и Матти оказываются в тюрьме, где Тапио умирает. Чуть позже Айно, увлеченная марксизмом, также попадает в тюрьму, терпит побои и насилие. Семья больше не в состоянии платить за аренду земли, и это окончательно укрепляет их в решении уехать в Америку, куда их давно зовет Илмари.

Все остальное повествование посвящено тому, как финны становятся финно-американцами, в чем им помогает тот самый неукротимый дух “sisu”. C необычайным упорством они корчуют лес, рыбачат, занимаются политической деятельностью, и их не останавливает то, что не все планы могут реализоваться так, как они задумывали. Так, Айно становится активисткой международной рабочей организации «Индустриальные рабочие мира» (ИРМ) (Industrial Workers of the World, IWW, известны также как Wobblies, уоббли). Ей противостоит не только ее работодатель, называющий ее «красной, как пожарное ведро», но и вся государственная машина, поскольку после принятия в 1917 г. «Закона о шпионаже» ее деятельность становится особенно опасной. Эта деятельность создает героине огромные проблемы и в личной жизни, но она не сдается. Не случайно ее имя вызывает аллюзию на историю непокорной Айно в «Калевале», предпочитающей умереть, но не выходить замуж за старика Вяйнямёйнена.

К. Марлантес подробно описывает участие героини в рабочем движении Америки. Он показывает финских иммигрантов, которые сделали очень много для самих американцев. Как уже было отмечено, именно они явились распространителями идей социализма по всей стране, и во многом благодаря такой одержимости, их духу "sisu", на предприятиях Мичигана был установлен 8-часовой рабочий день. 
Интересно, что один из авторов рецензии на книгу К. Марлантеса особо отмечает не столько финскую составляющую романа, сколько именно американскую. По его мнению, трое представителей одного семейства являются архетипическими фигурами, символизирующими американскую одержимость Богом, деньгами и политикой. «Илмари, пионер на земле, где «древесина была сокровищем, растущим ежедневно», охвачен страстью строительства процветающей церкви на вновь открытой земле обетованной. Точно так же его брат Матти, настоящий капиталист, с усердием работает над тем, чтобы открыть предприятие по производству лесозаготовительного оборудования. И, наконец, самая важная фигура - Айно, их сестра, которая прочитала «Манифест коммунистической партии» в 13 лет и выросла в активиста социалистического движения» [Athitakis 2019]. Это замечание представляется весьма важным в контексте определения гибридного характера финно-американской идентичности: оставаясь типичными финнами с духом "sisu”, они вместе с тем в новом контексте приобретают качества, присущие Америке, которая стала их вторым домом.

К. Марлантес, обращаясь к коллективному историческому прошлому и памяти о нем, подчеркивает важную мысль, которая часто встречается и в исследованиях по гибридной идентичности: художественные произведения «должны напоминать читателям всех этнических групп: чтобы по-настоящему ценить Америку, ни один человек не должен забывать о своем иммигрантском прошлом» [Lago D. 2004, 12]. В целом К. Марлантесу удалось в своем романе отразить основные стратегии определения финно-американской идентичности - изображение «финскости», обращение к опыту травмы и коллективной памяти, опору на архетипические образы «Калевалы».

Анализируя произведения финно-американских авторов, можно солидаризоваться с мнением М. Уоргелин-Браун [Wargelin-Brown 1994] о том, что «Калевала» остается главным творческим импульсом для финно-американских писателей: когда они начали использовать «Калевалу» как знак «финскости», одновременно стали создавать и финно-американскую литературу, которая отражала их жизнь в американском обществе.

\section{ЛИТЕРАТУРА} $487 \mathrm{c}$.

Американцы в поисках идентичности / Сост. И. В. Морозова. М.: Издательский центр РГГУ. 2013.

Бахтин М. М. Эстетика словесного творчества / Сост. С. Г. Бочаров. М.: Искусство. 1979. 423 с.

Бахтин М. М. Литературно-критические статьи. М.: Художественная литература, $1986.541 \mathrm{c.}$

Голубев А. В., Такала И. Р. В поисках социалистического Эльдорадо: североамериканские финны в Советской Карелии 1930-х годов. СПб.: Нестор-История, 2019. 352 с.

Калевала / пер. Л. П. Бельского. URL: http://kalevala.onegaborg.eu/Default.aspx?rune=10 (дата обращения 18.04.2021).

Коллективная память: власть прошлого в социокультурной жизни Америки. Ред. И. В. Морозова, В. И. Журавлева. М.: Издательский центр РГГУ, 2021. 317 с.

Кушнарева Е. С. Мультикультурализм в США // Исторические, философские, политические и юридические науки, культурология и искусствоведение. Вопросы теории и практики. 2011. № 7. С. 125-127.

Ракин H. A. «Калевала» на коми языке в контексте некоторых аспектов теории и практики художественного перевода. Тарту: University of Tartu Press, 2014. 338 c.

Тлостанова М. В. Проблема мультикультурализма и литература США конца XX века. М.: Наследие. ИМЛИ РАН, 2000. 400 с.

Anderson L. Children of the Kalevala: Contemporary American Finns Relive the Timeless Tales of the Kalevala. St. Cloud, MN: North Star Press of St. Cloud, 1997. 180 p.

Athitakis M. "Deep River" bucks every literary trend, and that's what makes it so charming // Washington Post, July 8.2019 URL: https://www.washingtonpost.com/entertainment/books/deep-river-bucks-every (accessed 04 July 2021).

Dykstra U. The Archetypal Finn: Finnishness as Constructed by Väinö Linna and The Song Of Haiawatha // Free online encyclopedia. URL: https://amp.ww.en.freejournal.org/449962/1/the-song-ofhiawatha.html / (accessed 02 July 2021). 
Handlin $O$. The Uprooted. The Epic Story of the Great Migration that Made the American People. Boston: University of Pennsylvania Press, 1952. 352 p.

Hoglund A. W. Finnish Immigrants in America, 1880-1920. Madison: University of Wisconsin Press, 1960. $213 \mathrm{p}$.

Kalm P. Travels into North America. Translated by John Reinhold Forster. 2d ed. London: T. Lowndes. 1772. E-Book .URL:https://www.loc.gov/resource/gdclccn.ca08002070/?st=gallery (accessed 10 June 2021).

Lago D. On the Viking Trail: Travels in Scandinavian America. Iowa City: University Of Iowa Press, 2004. $288 \mathrm{p}$.

Leonard D. P. The Finns in America: Their History and Their Literature. An Honors Thesis (HONRS 499). Muncie, Indiana. 2003. 39 p. URL: https://core.ac.uk/download/pdf/5009708.pdf/ (accessed 12 June 2021).

Marlantes K. Deep River. New York: Atlantic Monthly Press, 2019. 725 p.

Paananen E, Engle E. K. The Finns in America (In America Series). Minneapolis: Lerner Pub Group, 1978. $110 \mathrm{p}$.

Petaja E. The Cosmic Kalevala Book One: The Saga of Lost Earths. (Kindle Edition). New York: Page Turner Editions, 1979. 138 p.

Petaja E. The Cosmic Kalevala Book Two: The Star Mill (Kindle Edition). New York: Page Turner Editions, 2005. $128 \mathrm{p}$.

Petaja E. The Cosmic Kalevala Book Three: The Stolen Sun. (Kindle edition). New York: Page Turner Editions, 2005. 162 p.

Rajanen A. Of Finnish ways. New York: Barnes \& Noble Books, 1984. 224 p.

Taramaa R. Sisu As a Central Marker of Finnish-American Culture: Stubbornness beyond reason // American Studies in Scandinavia. 2009. Vol. 41. № 1. P. 36-60.

Tarkka L. The Displaced Bard // Journal of Finnish Studies. Vol. 13. № 2. 2009 Winter. P. 17-27.

The Finns in North America / Ed. by R. J. Jalkanen. East Lansing, 1969. 224 p.

Viihiimiiki B. Bringing the Kalevala to the World // Journal of Finnish Studies.Vol. 13. № 2. 2009 Winter. P. 1-4.

Virtanen B. L. Kalevala Incarnations in Finnish-American Science Fiction \& Fantasy // Journal of Finnish Studies.Vol. 13. № 2. 2009 Winter. P. 85-94.

Wargelin-Brown M. The Kalevala as western culture in Finland and America // The best of Finnish Americana. Ed.by M. Kami. Iowa City. I A: Penfield Press, 1994. P. 180-195.

Поступила в редакцию 19.09.2021

Морозова Ирина Васильевна, доктор филологических наук, профессор, Российский государственный гуманитарный университет, 125993, Россия, г. Москва, Миусская пл., 6, e-mail: irinamoro@gmail.com

\title{
I. V. Morozova \\ FINNISH AMERICAN IDENTITY AND STRATEGIES FOR ITS DETERMINATION IN FINNISH AMERICAN CONTEMPORARY LITERATURE
}

\author{
DOI: $10.35634 / 2224-9443-2021-15-4-642-653$
}

The article focuses on one of the pressing problems of modern humanitarian knowledge - the problem of selfidentification of hybrid cultures, in particular, the culture of the Finnish Americans. The ethnic diversity of the United States leads to a constant intersection of various cultures, giving rise to the uniqueness of contemporary American literary life. National, cultural, personal identity associated with the revision of the traditions that were assimilated in their diaspora acts as the main problem of multiculturalism - the ideology of plurality and diversity. Self-identification strategies may include the definition of one's religious, ethnic, gender determination. Very often, the community's collective trauma and collective memory of the historical past can act as a strategy. The main strategies of ethnic and cultural self-identification of Finnish American literature are represented by the collective memory, collective trauma, "Finnishness", and the national Finnish epic "Kalevala", which is used 
as a source of archetypal images and poetic imagination. Basing on a number of works by Finnish American writers of the second half of the $20^{\text {th }}$ and $21^{\text {st }}$ centuries in different genres (science fiction, historical novel, short stories), the article examines the creative application of the Finnish epic "Kalevala", integrated into the experience of American existence as one of the main strategies for self-identification of its own culture, which is built on the dialogical interaction of the Anglo-Saxon and Finnish cultures. The article actualizes the problems of the interrelations of the two cultures, the transformation of archetypal images, the reflection of collective memory in the works of contemporary Finnish American writers.

Keywords: Finnish American literature, hybrid identity, dialogue of cultures, multiculturalism, collective memory, "finnishness", "Kalevala", Emil Petaja, Lauri Anderson, Karl Marlantes.

Citation: Yearbook of Finno-Ugric Studies, 2021, vol. 15, issue 4, pp. 642-653. In Russian.

\section{REFERENCES}

Americans in the pursuit of the identity / Comp. I. V. Morozova [Amerikantsy v gjbskakh identichnosti/ Sost. I. V. Morozova]. Moscow: Izdatelsky Tsentr RGGU. 2013. 487 p. In Russian.

Anderson L. Children of the Kalevala: Contemporary American Finns Relive the Timeless Tales of the Kalevala. St. Cloud, MN: North Star Press of St. Cloud. 1997. 180 p.

Athitakis M. "Deep River" bucks every literary trend, and that's what makes it so charming // Washington Post. July 8. 2019 URL: https://www.washingtonpost.com/entertainment/books/deep-river-bucks-every-li (accessed 04 July 2021).

Bahktin M. M. Aesthetics if the word / Comp. by S. G. Bocharov [Bahktin M. M. Aestetika slovesnogo tvorchestva / Sost. S. G. Bocharov]. Moscow: Iskusstvo. 1979. 423 p. In Russian.

Bahktin M. M. Literaturno-kriticheskiye statyi [Bahktin M. M. Literary criticism essays]. Moscow: Khudozhestvennaya literature. 1986. 541 p. In Russian.

Dykstra U. The Archetypal Finn: Finnishness as Constructed by Väinö Linna and Kalle Päätalo // Journal of Finnish Studies. 2008. Vol. 12. № 1. P. 33-47. In English.

The Song of Hiawatha // Free online encyclopedia. URL: https://amp.ww.en.freejournal.org/449962/1/ the-song-of-hiawatha.html / (accessed 02 July 2021). In English.

Golubev A. V., Takala I. R. The Search for a Socialist El Dorado: Finnish Immigration to Soviet Karelia from the United States and Canada in the $1930 \mathrm{~s}$. [V poiskakh sotsialisticheskogo Eldorado: severoamericanskiye finny v Sovetskoy Karelii 1930k ${ }^{\mathrm{kh}}$ godov]. S-Petersburg: Nestor-Istoria. 2019. 352 c.

Handlin O. The Uprooted. The Epic Story of the Great Migration that Made the American People. Boston: University of Pennsylvania Press. 1952. 352 p. In English.

Hoglund A. W. Finnish Immigrants in America, 1880-1920. Madison: University of Wisconsin Press. 1960. 213 p. In English.

Kalevala / per. L. P. Belskogo [Kalevala transl. by L. P. Belsky]. URL: http://kalevala.onegaborg.eu/ Default.aspx?rune=10 (accessed 18 April 2021). In Russian.

Kalm P. Travels into North America. Translated by John Reinhold Forster. $2 d$ ed. London: T. Lowndes. 1772. E-Book. URL: https://www.loc.gov/resource/gdclccn.ca08002070/?st=gallery (accessed 10 June 2021).

Collective memory: power of the past in sociocultural life of America. Ed. by I. V. Morozova, V. I. Zhuravleva [Kollectivnaya pamyat': vlast' proshlogo v sociokulturnoy zhizni Ameriki. Red. I. V. Morozova, Vol. I. Zhuravleva], Moscow: Izdatelsky Tsentr RGGU. 2021. 317 p.

Kushnaryova E. S. Multi-Culturalism in the USA THE USA [Multikulturalism v SSha] Istoricheskiye, philosophskiye, politicheskiye i yuridicheskiye nauki, kulturilogiya i iskusstvovedeniye. Voprosy teorii i praktiki [Historical, philosophical, political and legal sciences. Theory and Practice]. 2011. № 7. P. 125-127. In Russian.

Lago D. On the Viking Trail: Travels in Scandinavian America. Iowa City: University Of Iowa Press. 2004. 288 p. In English.

Leonard D. P. The Finns in America: Their History and Their Literature. An Honors Thesis (HONRS 499). Muncie. Indiana. 2003. 39 p. In English.

Marlantes K. Deep River. New York: Atlantic Monthly Press. 2019. 725 p.

Paananen E., Engle E. K. The Finns in America (In America Series). Minneapolis: Lerner Pub Group. 1978. 110 p. In English. 
Petaja E. The Cosmic Kalevala Book One: The Saga of Lost Earths. (Kindle Edition). New York: Page Turner Editions. 1979. 138 p.

Petaja E. The Cosmic Kalevala Book Two: The Star Mill (Kindle Edition). New York: Page Turner Editions. 2005. 128 p.

Petaja E. The Cosmic Kalevala Book Three: The Stolen Sun. (Kindle edition). New York: Page Turner Editions. 2005. 162 p.

Rajanen A. Of Finnish ways. New York: Barnes \& Noble Books. 1984. 224 p. In English.

Rakin N. A. The "Kalevala" epic in the komi language: some aspects of the theory and practice of translation [Rakin N. A. "Kalevala" na komi yazyke v kontekste nekotorykh aspektov teorii i praktiki khudozhestvennogo perevoda]. Tartu: University of Tartu Press. 2014. 338 p. In Russian.

Taramaa R. Sisu As a Central Marker of Finnish-American Culture: Stubbornness beyond reason. American Studies in Scandinavia. 2009. Vol. 41. № 1. P. 36-60. In English.

Tarkka L. The Displaced Bard. Journal of Finnish Studies. Vol. 13. № 2. 2009 Winter. P. 17-27. In English.

Tlostanova M. V. Problem of multiculturalism and literature of the USA of the end of the XX century [Tlostanova M.V.Problema multiculturalisma b literatury SShA kont. XX v.] Moscow: Naslediye. IMLI RAN. 2000. 400 p. In Russian.

The Finns in North America / Ed.by R. J .Jalkanen. East Lansing. 1969. 224 p. In English.

Viihiimiiki B. Bringing the Kalevala to the World //Journal of Finnish Studies.Vol. 13. № 2. 2009 Winter. P. 1-4. In English.

Virtanen B. L. Kalevala Incarnations in Finnish-American Science Fiction \& Fantasy. Journal of Finnish Studies.Vol. 13. № 2. 2009 Winter. P. 85-94. In English.

Wargelin-Brown M. The Kalevala as western culture in Finland and America // The best of Finnish Americana. Ed. by M. Kami. Iowa City, I A: Penfield Press. 1994. P. 180-195. In English.

Received 19.09.2021

Morozova Irina Vasilyevna, Doctor Hab. in Philology, Professor, Russian State University for the Humanities, 6, Miuskaya sq., Moscow, 125993, Russian Federation, e-mail: irinamoro@gmail.com 